\title{
Avaliação de fontes de nitrogênio e épocas de aplicação em cobertura para o cultivo do trigo
}

\section{Evaluation of sources of nitrogen and times of application in top dressing for the cultivation of the wheat}

\author{
Gilberto Takeo Yano ${ }^{1 *}$; Hideaki W. Takahashi ${ }^{1}$; Toshio S. Watanabe ${ }^{2}$
}

Resumo

O objetivo deste trabalho foi testar fontes de nitrogênio e épocas de aplicação em cobertura para a cultura do trigo na região de Mauá da Serra. Foi utilizado a cultivar de trigo CD-104 em sistema de semeadura direta, utilizando o espaçamento entre plantas de $0,17 \mathrm{~m}$ na densidade de 350 sementes por metro quadrado.Na adubação de base foi aplicado $400 \mathrm{kgha}^{-1}$ do adubo formulado 10-20-10. Os tratamentos se constituiram de 3 fontes de nitrogênio (Uréia, Sulfato de Amônio e Nitrato de Amônio), aplicados a lanço em 3 épocas (logo após a semeadura, no perfilhamento e no emborrachamento), totalizando 9 tratamentos. Cada parcela foi constituída por uma área de $4 \mathrm{~m}$ x $5 \mathrm{~m}$ sendo considerada como área útil as 5 linhas centrais. O delineamento experimental utilizado foi o de blocos ao acaso com 4 repetições. Os resultados demostraram não haver diferença no rendimento de grãos entre fontes nem entre as épocas de aplicação. Já nos aspectos relacionados à qualidade do grão, foi observado que a aplicação na época do emborrachamento da cultura, propiciou uma produção de grãos de melhor qualidade com maior peso e teor de proteína.

Palavras-chave: Triticum aestivum L, nitrogênio, adubação, nutrição de plantas

\begin{abstract}
The objective of this work was to test sources of nitrogen and application times in top dressing for the wheat crop in the area of Mauá da Serra-Pr. It was used wheat 'CD-104' in direct sowing system, using a spacing between plants of $0.17 \mathrm{~m}$ and a density of 350 seeds $\mathrm{m}^{-2}$, being accomplished a base fertilizer applying $400 \mathrm{~kg} \mathrm{ha}^{-1}$ of the formulated fertilizer 10-20-10. The treatments had been constituted of 3 sources of nitrogen (Urea, Sulfate of Ammonium and Nitrate of Ammonium), applied in broadcasting in 3 different times (soon after the sowing, in the tillering and in the booting), resulting in 9 treatments. Each parcel was constituted by an area of $4.0 \mathrm{~m} \times 5.0 \mathrm{~m}$ being considered as useful area the 5 central lines. The used experimental design was of blocks at random with 4 replications. There are no differences in the yield of grains among sources of $\mathrm{N}$ not even for the application times. The late application at the booting of the crop caused a production of grains of better quality with larger weight and protein content.
\end{abstract}

Key words: Triticum aestivum $\mathrm{L}$, nitrogen, manuring, plant nutrition

1 Professor do Departamento de Agronomia, UEL. C.P. 6001. CEP 86.051-990. Londrina. PR. Tel.43 3371-4784. E-mail: hwilson@uel.br

2 Engenheiro Agrônomo

* Autor para correspondência. 


\section{Introdução}

O trigo (Triticum aestivum L.) é um dos cereais mais consumidos, tendo como principais produtores mundiais os Estados Unidos, a Comunidade Européia, Rússia e China. (VIEIRA, 2003).

O nitrogênio tem grande importância para a cultura do trigo devido a sua participação na constituição de substâncias determinantes da qualidade e no desenvolvimento de funções metabólicas essenciais, tais como a síntese protéica. (VIEIRA et al. 1995).

Segundo Mielniczuk (1982), a matéria orgânica é a principal fonte de $\mathrm{N}$ do solo para as culturas. Pela ação microbiana o nitrogênio dos compostos orgânicos é liberado na forma amoniacal $\left(\mathrm{NH}_{4}^{+}\right)$, que é oxidada no solo para a forma nítrica $\left(\mathrm{NO}_{3}^{-}\right)$. Porém devido à alta exigência de nitrogênio pela cultura do trigo deve-se complementar o nitrogênio fornecido pela matéria orgânica através de adubação nitrogenada.

As fontes de nitrogênio para as culturas podem ser tanto na forma nítrica $\left(\mathrm{NaNO}_{3}, \mathrm{KNO}_{3}\right)$, amoniacal $\left[\left(\mathrm{NH}_{4}\right)_{2} \mathrm{SO}_{4}\right]$, nítrico-amoniacal $\left(\mathrm{NH}_{4} \mathrm{NO}_{3}\right)$ e amídica (uréia) (Mielniczuk, 1982). Entre essas, a uréia é a mais utilizada na agricultura brasileira, sendo a mais concentrada $(45 \%$ de $\mathrm{N})$ e conseqüentemente de menor custo. O sulfato de amônio apesar de ser menos concentrado ( $21 \%$ de $\mathrm{N})$, e de maior custo, tem algumas vantagens como o fornecimento adicional de enxofre. $\mathrm{O}$ nitrato de amônio é menos utilizado do que os anteriores, possuindo uma concentração de N intermediária entre o sulfato de amônio e a uréia $(32 \%$ de $N)$, tem um custo mais elevado, porém seu uso pode ser interessante em alguns casos de aplicação superficial.

Porém, em anos de deficiência hídrica durante o ciclo da cultura do trigo, os incrementos na produção proporcionados pelo uso de sulfato de amônio em relação à uréia, nas mesmas doses de nitrogênio, são significativos (Oliveira \& Balbino,1995).
Peruzzo, Siqueira e Wietholter(1994), comparando a eficiência agronômica de vários fertilizantes nitrogenados na aplicação em cobertura na cultura do trigo, não observaram diferenças no rendimento de grãos entre as fontes de nitrogênio uréia, nitrato de amônia e sulfato de amônia

Já Nakayama, Fabricio e Santos (1983), realizando experimento com adubação testando diferentes doses e épocas de aplicação de $\mathrm{N}$ em cobertura no trigo na UEPAE Dourados, não verificaram diferenças significativas na produção, peso hectolítrico e peso de mil grãos.

O período crítico de suprimento de $\mathrm{N}$ em trigo vai da emergência até a emissão da $7^{\mathrm{a}}$ folha. Nos estádios iniciais deste período, o $\mathrm{N}$ é necessário para potencializar o número máximo de espiguetas por espiga e, em conseqüência, o número de grãos por espigas, enquanto, nos estádios finais do período, o $\mathrm{N}$ é crítico para determinar o número de colmos por área .(BREDEMEIER; MUNDSTOCK, 2001).

O presente trabalho teve por objetivo realizar em condições de campo, avaliações do efeito de diferentes fontes de nitrogênio e épocas de aplicação em cobertura para a cultura do trigo, na região de Mauá da Serra-PR, em sistema de semeadura direta.

\section{Material e Métodos}

O experimento foi conduzido a campo em Latossolo Roxo de textura argilosa, localizado no Município de Mauá da Serra - PR ( Latitude: $23^{\circ}$ 50', Longitude: 51 $11^{\circ}$, Altitude: $935 \mathrm{~m}$ ). O local apresenta clima subtropical mesotérmico, de verões frescos e com ocorrência de geadas freqüentes, não apresentando estações secas definidas. O solo cultivado por vários anos sob sistema de semeadura direta apresentava-se com fertilidade razoavelmente elevada e com quantidade de matéria orgânica também elevada. O resultado da análise química do solo está apresentado na Tabela 1. 
Tabela 1. Resultados da análise química do solo constituinte da camada arável 0-10 $\mathrm{cm}$ e 10-20cm. Mauá da SerraPR.,2003.

\begin{tabular}{rrrccccccccc}
\hline Prof. & $\begin{array}{r}\mathrm{M} . \mathrm{O} \\
\mathrm{g} / \mathrm{dm}^{3}\end{array}$ & $\begin{array}{c}\mathrm{pH} \\
\mathrm{CaCl}_{2}\end{array}$ & $\begin{array}{c}\mathrm{P} \\
\mathrm{mgdm}^{-3}\end{array}$ & $\begin{array}{c}\mathrm{Al} \\
--------\mathrm{cmol}_{\mathrm{c}} / \mathrm{dm}^{-3}----------\end{array}$ & $\begin{array}{c}\mathrm{Mg} \\
\mathrm{H}+\mathrm{Al}\end{array}$ & $\begin{array}{c}\mathrm{CTC} \\
\mathrm{pH} 7\end{array}$ & $\begin{array}{c}\mathrm{CTC} \\
\text { efetiva }\end{array}$ & $\begin{array}{r}\mathrm{V} \\
\%\end{array}$ \\
\hline $00-10 \mathrm{~cm}$ & 54,9 & 4,5 & 47,50 & 0,0 & 0,29 & 4,70 & 1,10 & 9,4 & 15,49 & 6,26 & 39,3 \\
$10-20 \mathrm{~cm}$ & 35,7 & 4,6 & 25,78 & 0,0 & 0,23 & 4,00 & 1,20 & 9,0 & 14,43 & 5,65 & 37,6 \\
\hline
\end{tabular}

Os tratamentos, constaram de fatorial $3 \times 3$ envolvendo 3 fontes de nitrogênio (nitrato de amônio, sulfato de amônio e uréia), e 3 épocas de aplicação em cobertura (plantio, perfilhamento e emborrachamento).

O delineamento experimental utilizado foi blocos ao acaso com 9 tratamentos e 4 repetições, com parcelas experimentais de 4,0 de largura por 5,0 m de comprimento, tendo uma área de $20 \mathrm{~m}^{2}$, sendo considerada como área útil $2 \mathrm{~m}^{2}$ centrais.

A cultura antecessora ao trigo foi o milho, sendo que antes da semeadura do trigo foi realizada uma roçada para homogeneizar a palhada, com posterior aplicação do herbicida glifosate (720 g há-1) para eliminar as plantas daninhas. A semeadura foi realizada no dia 14 de junho de 2003, sob sistema de semeadura direta utilizando uma semeadora tratorizada com espaçamento entre linhas de $0,17 \mathrm{~m}$ e com uma densidade de 350 sementes por metro quadrado. Na adubação de plantio foi feita aplicação $400 \mathrm{~kg} \mathrm{ha}^{-1}$ do adubo formulado 10-20-10, no sulco de plantio em toda a área, correspondendo a $40 \mathrm{~kg}$ de $\mathrm{N}$ por hectare.

A cultivar de trigo utilizada no experimento foi a CD-104, sendo recomendada para as regiões 6, 7 e 8 do Paraná. Essa cultivar apresenta ciclo médio, em torno de 74 dias para o espigamento e 118 dias para a maturação. Pertence a classe comercial tipo melhorador e com um peso do hectolitro médio de 78. Apresenta altura de planta baixa, sendo resistente ao acamamento. Para complementar a adubação de plantio foram realizadas adubações nitrogenadas em cobertura com $50 \mathrm{~kg} /$ ha utilizando três fontes e três épocas de aplicação como segue: T1- Sulfato de amônio aplicado logo após a semeadura; T2- Sulfato de amônio aplicado no perfilhamento; T3-Sulfato de amônio aplicado no emborrachamento; T4- Uréia aplicada logo após a semeadura; T5- Uréia aplicada no perfilhamento; T6- Uréia aplicada no emborrachamento; T7- Nitrato de amônio aplicado logo após o plantio; T8- Nitrato de amônio aplicado no perfilhamento; T9- Nitrato de amônio aplicado no emborrachamento.

Dessa forma, logo após o plantio foram aplicados $50 \mathrm{~kg}$ de $\mathrm{N}$ por hectare nos tratamento 1,4 e 7 utilizando, respectivamente, sulfato de amônia, uréia e nitrato de amônia a lanço. No dia 29 de julho, quando as plantas apresentavam-se no estágio de perfilhamento, foi realizada a aplicação de nitrogênio em cobertura nos tratamentos 2, 5 e 8 utilizando, respectivamente sulfato de amônia, uréia e nitrato de amônia. A adubação de cobertura nos tratamentos 3, 6 e 9 foi realizada no dia 17 de agosto quando as plantas apresentavam-se no estádio de emborrachamento, aplicando respectivamente sulfato de amônia, uréia e nitrato de amônia.

O controle das plantas daninhas foi mediante aplicação do herbicida metsulfuron metil (na dose de $5 \mathrm{~g}$ há $^{-1}$ do produto comercial Ally), com $0,1 \% \mathrm{v} / \mathrm{v}$ de óleo mineral, no dia 26 de julho de 2003, quando as ervas daninhas apresentavam-se com 4 a 6 folhas.

O controle de pragas foi feito com duas aplicação de inseticidas, a primeira realizada no dia 26 de julho com aplicação do inseticida fisiológico Triflumuron (na dose de $60 \mathrm{~mL} \mathrm{ha}^{-1}$ do produto comercial Certero), para controle de lagartas, e a segunda realizada na época do enchimento de grãos com aplicação do inseticida Triflumuron (na dose de $60 \mathrm{~mL} \mathrm{ha}^{-1}$ do produto comercial Certero), juntamente com inseticida Metamidofós (na dose de 0,2 $\mathrm{L} \mathrm{ha}^{-1}$ do produto comercial Tamaron) para controle, respectivamente, de lagartas e pulgões. 
Para controle de doenças foram realizadas duas aplicações do fungicida tebuconazole (na dose de 0,75 $\mathrm{L} \mathrm{ha}^{-1}$ do produto comercial Folicur), aplicados no florescimento e no enchimento de grãos.

\section{As características avaliadas foram:}

a) Teor de nitrogênio em folha índice: para a determinação de teor de nitrogênio nas folhas foram feitas coletas de 30 folhas bandeiras por parcela na época do florescimento. Essas folhas foram lavadas, secadas, pesadas e moídas para posteriormente realizar-se a determinação do teor de nitrogênio;

b) Altura de plantas: foram feitas medições da altura de 50 plantas ao acaso por parcela,do colo ao ápice da planta;

c) $\mathrm{N}^{\mathrm{o}}$ de plantas por metro quadrado: foi obtida através da contagem do número de plantas na área de $2 \mathrm{~m}^{2}$ centrais;

d) $\mathrm{N}^{\mathrm{o}}$ de espigas por metro quadrado: foi obtida através da contagem do número de espigas na área de $2 \mathrm{~m}^{2}$ centrais;

e) Número de grãos por espiga: foi obtida através da contagem do número de grãos em 30 espigas ao acaso por parcela;

f) Rendimento de grãos: para a determinação do rendimento de grãos foi feita a colheita manual na área central de $2 \mathrm{~m}^{2}$ por parcela, sendo o material trilhado mecanicamente, e pesado. Posteriormente foi feita determinação do teor de umidade do grão para posterior correção do peso a 13\% de umidade;

g) Peso de 1000 grãos: foi obtido através da contagem e pesagem de duas subamostras de 1000 grãos para cada parcela;

h) Peso do hectolitro: representa o peso dos grãos por unidade de volume (kilogramas/hectolitro), e foi determinada através da balança de peso do hectolitro;

i) Teor de proteína do grão: para obtenção do teor proteína do grão, primeiramente foi determinado o teor de nitrogênio pelo método de Kjedahl, sendo posteriormente determinado o teor de proteína, através do fator de conversão (\%proteína $=\% \mathrm{~N}$ x 5,7).

\section{Resultados e Discussão}

Na Tabela 2 estão apresentados os resultados do peso de matéria seca da parte aérea de plantas coletadas em diferentes estádios de desenvolvimento. Na primeira coleta realizada no dia 26 de julho, estádio de perfilhamento, foi verificado um menor peso da matéria seca nos tratamentos que receberam adubação de cobertura utilizando uréia como fonte de nitrogênio em relação ao sulfato de amônia e o nitrato de amônio, isso pode ter ocorrido pois após a aplicação ocorreu uma longa estiagem o que pode ter reduzido a eficiência da uréia. Já entre as épocas, a aplicação de nitrogênio em cobertura logo após o plantio resultou na maior produção de matéria seca nas plantas em relação aos demais tratamentos que não haviam recebido adubação de cobertura até essa data.

Tabela 2. Matéria seca em $\mathrm{g} \mathrm{m} \mathrm{-}^{2}$ da parte aérea de plantas coletadas nos estágios de perfilhamento, emborrachamento e enchimento de grãos em função dos tratamentos. Mauá da Serra, Pr.

\begin{tabular}{lccc}
\hline TRATAMENTOS & Perfilhamento & Emborrachamento & Enchimento de grãos \\
\hline Fontes de N & $52,22 \mathrm{a}^{1}$ & $232,01 \mathrm{a}$ & $639,05 \mathrm{a}$ \\
Sulfato de amônia & $39,82 \mathrm{~b}$ & $213,04 \mathrm{a}$ & $674,29 \mathrm{a}$ \\
Uréia & $51,92 \mathrm{a}$ & $214,21 \mathrm{a}$ & $649,52 \mathrm{a}$ \\
$\quad$ Nitrato de amônia & & & \\
\hline Época de aplicação & $54,49 \mathrm{a}$ & $222,68 \mathrm{a}$ & $653,33 \mathrm{a}$ \\
Plantio & $44,28 \mathrm{~b}$ & $222,55 \mathrm{a}$ & $638,10 \mathrm{a}$ \\
Perfilhamento & $45,19 \mathrm{~b}$ & $214,04 \mathrm{a}$ & $671,43 \mathrm{a}$ \\
Emborrachamento & & & \\
\hline Valores de F & $1,78 \mathrm{~ns}$ & $2,34 \mathrm{~ns}$ & $0,54 \mathrm{~ns}$ \\
Bloco & $7,07 * *$ & $0,38 \mathrm{~ns}$ & $0,14 \mathrm{~ns}$ \\
Fonte & $4,51 * *$ & $0,08 \mathrm{~ns}$ & $0,12 \mathrm{~ns}$ \\
Época & $0,76 \mathrm{~ns}$ & $0,36 \mathrm{~ns}$ & $1,46 \mathrm{~ns}$ \\
Fonte x Época & 19,21 & 27,22 & 25,38 \\
\hline C.V. (\%) & &
\end{tabular}

Obs: n.s. - não significativo ao nível de $1 \%$ de probabilidade; * - significativo ao nível de $5 \%$ de probabilidade; $* *$ - significativo ao nível de $1 \%$ de probabilidade; 1 - as médias seguidas de letras diferentes são estatisticamente distintas entre si de acordo com o teste de Tukey, ao nível de 1\% de probabilidade. 
No emborramento e no perfilhamento não foram verificadas diferenças significativas na peso de matéria seca para fontes e épocas de aplicação.

$\mathrm{Na}$ tabela 3 podem ser observados os teores médios de nitrogênio presentes nas plantas de trigo, porém não foram verificadas diferenças significativas no teor de $\mathrm{N}$ entre os tratamentos. Resultado semelhante foi obtido por Peruzzo e Siqueira. (1994) que não verificaram diferenças no teor de $\mathrm{N}$ na parte aérea de plantas de trigo coletadas aos 90 dias após o plantio entre as fontes de nitrogênio uréia, nitrato de amônia e sulfato de amônia. Isto significa que a reserva de matéria orgânica, teor de $54,9 \mathrm{~g} \mathrm{dm}^{-3}$, na camada 00-10 cm, foi suficiente para suprir a necessidade das plantas de trigo.

Tabela 3. Teor de nitrogênio $\left(\mathrm{g} \mathrm{kg}^{-1}\right)$ na matéria seca na parte aérea de plantas de trigo coletadas nos estágios de perfilhamento, emborrachamento e enchimento de grãos.

\begin{tabular}{lccc}
\hline TRATAMENTOS & Perfilhamento & Emborrachamento & Enchimento de grãos \\
\hline Fontes de N & $48,73 \mathrm{a}^{1}$ & $32,83 \mathrm{a}$ & $16,35 \mathrm{a}$ \\
Sulfato de amônia & $49,91 \mathrm{a}$ & $33,59 \mathrm{a}$ & $14,55 \mathrm{a}$ \\
Uréia & $48,66 \mathrm{a}$ & $32,47 \mathrm{a}$ & $15,54 \mathrm{a}$ \\
Nitrato de amônia & & & \\
\hline Épocas de aplicação & $50,02 \mathrm{a}$ & $33,77 \mathrm{a}$ & $15,06 \mathrm{a}$ \\
\hline Plantio & $48,62 \mathrm{a}$ & $33,74 \mathrm{a}$ & $16,81 \mathrm{a}$ \\
Perfilhamento & $48,66 \mathrm{a}$ & $31,38 \mathrm{a}$ & $14,58 \mathrm{a}$ \\
Emborrachamento & & $0,17 \mathrm{~ns}$ & $4,23 *$ \\
\hline Valores de F & $1,48 \mathrm{~ns}$ & $0,22 \mathrm{~ns}$ & $3,35 \mathrm{~ns}$ \\
Bloco & $0,33 \mathrm{~ns}$ & $1,24 \mathrm{~ns}$ & $2,70 \mathrm{~ns}$ \\
Fonte & $0,42 \mathrm{~ns}$ & $0,69 \mathrm{~ns}$ & $0,45 \mathrm{~ns}$ \\
Época & $0,70 \mathrm{~ns}$ & 12,90 & 11,01 \\
Fonte x Época & 8,70 & &
\end{tabular}

Obs: n.s. - não significativo ao nível de $1 \%$ de probabilidade; * - significativo ao nível de $5 \%$ de probabilidade; $* *$ - significativo ao nível de $1 \%$ de probabilidade; 1 - as médias seguidas de letras diferentes são estatisticamente distintas entre si de acordo com o teste de Tukey, ao nível de 1\% de probabilidade.

$\mathrm{Na}$ tabela 4 encontram-se os resultados da quantificação de matéria seca e teor de nitrogênio em folhas bandeiras das plantas de trigo coletadas na época do florescimento. Os resultados obtidos demonstraram que os tratamentos que receberam adubação nitrogenada em cobertura logo após o plantio apresentaram uma maior quantidade de matéria seca da folha bandeira em relação à aplicação na época do emborrachamento, já a aplicação no perfilhamento teve um valor intermediário entre as duas épocas não tendo se diferenciado significativamente.

Tabela 4. Matéria seca e teor foliar de nitrogênio em folhas bandeiras coletadas na época do florescimento. Mauá da Serra, Pr.

\begin{tabular}{lcc}
\hline TRATAMENTOS & Peso MS (g/30 folhas) & Teor de N $\left(\mathbf{g ~ k g}^{-1} \mathbf{~ d e ~ m s}\right)$ \\
\hline Fontes de nitrogênio & $4,10 \mathrm{a}^{1}$ & $46,54 \mathrm{a}$ \\
Sulfato de amônia & $4,06 \mathrm{a}$ & $46,21 \mathrm{a}$ \\
Uréia & $3,89 \mathrm{a}$ & $45,63 \mathrm{a}$ \\
Nitrato de amônia & & \\
\hline Épocas de aplicação & $4,38 \mathrm{a}$ & $44,16 \mathrm{~b}$ \\
Plantio & $4,02 \mathrm{ab}$ & $46,39 \mathrm{a}$ \\
Perfilhamento & $3,65 \mathrm{~b}$ & $47,84 \mathrm{a}$ \\
Emborrachamento & $3,26 *$ & $6,16 * *$ \\
\hline Valores de F & $0,92 \mathrm{~ns}$ & $0,65 \mathrm{~ns}$ \\
Bloco & $10,28 * *$ & $10,39 * *$ \\
Fonte & $1,66 \mathrm{~ns}$ & $0,98 \mathrm{~ns}$ \\
Época & $9,83 \%$ & 4,32 \\
Fonte x Época & & \\
\hline C.V. (\%) &
\end{tabular}

Obs: n.s. - não significativo ao nível de $1 \%$ de probabilidade; * - significativo ao nível de $5 \%$ de probabilidade; $* *$ - significativo ao nível de $1 \%$ de probabilidade; 1 - as médias seguidas de letras diferentes são estatisticamente distintas entre si de acordo com o teste de Tukey, ao nível de $1 \%$ de probabilidade.

Por outro lado quando a aplicação de nitrogênio foi realizada mais tardiamente, no emborrachamento as folhas apresentaram-se com maior teor de nitrogênio na época do florescimento.

Em relação às diferentes fontes de nitrogênio não houve diferença significativa para peso de matéria seca e para teor de nitrogênio em folhas.

Os valores encontrados na análise foliar de nitrogênio ficaram em torno de $46 \mathrm{~g}$ de $\mathrm{N}$ por $\mathrm{kg}$ de matéria seca, esses valores estão muito acima do considerado adequado de acordo com Malavolta, Vitti e Oliveira. (1997), que considera como adequado os valores entre 30 a 33 gramas de $\mathrm{N}$ por kilograma de 
matéria seca. Portanto o fornecimento de nitrogênio à planta foi mais que suficiente de acordo com a literatura, o que pode ter colaborado para a não verificação de diferença significativa entre as fontes nitrogenadas e época de aplicação.

$\mathrm{Na}$ tabela 5 encontram-se os resultados de altura de plantas, número de plantas e de espigas por metro quadrado. A altura de plantas demonstrou que a aplicação antecipada de nitrogênio favoreceu o desenvolvimento, porém entre as fontes não houve diferenças significativa.

Tabela 5. Altura média, número de plantas e de espigas por metro quadrado, em função de fontes de nitrogênio e épocas de aplicação. Mauá da Serra, Pr.

\begin{tabular}{|c|c|c|c|}
\hline TRATAMENTOS & $\begin{array}{l}\text { Altura média } \\
\qquad \text { (cm) }\end{array}$ & Plantas $/ \mathbf{m}^{2}$ & Espigas $/ \mathbf{m}^{2}$ \\
\hline \multicolumn{4}{|l|}{ Fontes de nitrogênio } \\
\hline Sulfato de amônia & $74,89 \mathrm{a}^{1}$ & 89,42 a & $253,08 \mathrm{a}$ \\
\hline Uréia & $75,54 \mathrm{a}$ & $91,92 \mathrm{a}$ & $269,67 \mathrm{a}$ \\
\hline Nitrato de amônia & $74,26 \mathrm{a}$ & $86,92 \mathrm{a}$ & $265,58 \mathrm{a}$ \\
\hline \multicolumn{4}{|l|}{ Épocas de aplicação } \\
\hline Plantio & $76,47 \mathrm{a}$ & $84,75 \mathrm{a}$ & $260,67 \mathrm{a}$ \\
\hline Perfilhamento & $74,70 \mathrm{ab}$ & $92,50 \mathrm{a}$ & $275,75 \mathrm{a}$ \\
\hline Emborrachamento & $73,52 \mathrm{~b}$ & $91,00 \mathrm{a}$ & $251,92 \mathrm{a}$ \\
\hline \multicolumn{4}{|l|}{ Valores de F } \\
\hline Bloco & $1,49 \mathrm{~ns}$ & $13,09 * *$ & $5,56 * *$ \\
\hline Fonte & $1,28 \mathrm{~ns}$ & $0,98 \mathrm{~ns}$ & $1,32 \mathrm{~ns}$ \\
\hline Época & $6,95 * *$ & $2,64 \mathrm{~ns}$ & $2,58 \mathrm{~ns}$ \\
\hline Fonte x Época & $2,73 \mathrm{~ns}$ & $1,53 \mathrm{~ns}$ & $1,66 \mathrm{~ns}$ \\
\hline C.V. $(\%)$ & 2,61 & $9,81 \%$ & $9,90 \%$ \\
\hline
\end{tabular}

Obs: n.s. - não significativo ao nível de $1 \%$ de probabilidade; * - significativo ao nível de $5 \%$ de probabilidade; ** - significativo ao nível de $1 \%$ de probabilidade; 1 - as médias seguidas de letras diferentes são estatisticamente distintas entre si de acordo com o teste de Tukey, ao nível de 1\% de probabilidade.

Em relação ao número de plantas e de espigas por metro quadrado não foram verificadas diferenças significativas entre os tratamentos.

Na tabela 6 encontram-se os resultados do rendimento de grãos, peso de mil grãos, peso hectolítrico e teor de proteína nos grãos. Como pode ser observado, não foram verificadas diferenças significativas para produção de grãos entre a fontes testadas. As épocas de aplicações influenciaram nas variáveis peso de 1000 grãos e teor de proteína. Trabalhos realizados por Peruzzo, Siqueira e Wietholter (1994), Oliveira e Balbino (1995), Cantarella et al. (1988), não encontraram diferenças na eficiência destas fontes em condições de campo. Para as épocas de aplicação de $\mathrm{N}$ em cobertura, Nakayama et al. (1983) e Vieira et al. (1995) também não verificaram diferenças no rendimento do trigo entre as épocas de aplicação em cobertura.

Tabela 6. Rendimento de grãos, peso de 1000 grãos, peso do hectolitro e teor de proteína do grão de trigo em função de fontes e épocas de aplicação de nitrogênio. Mauá da Serra, Pr.

\begin{tabular}{lcccc}
\hline TRATAMENTOS & $\begin{array}{c}\text { Produtividade } \\
\left(\mathbf{k g ~ h a}^{-1}\right)\end{array}$ & $\begin{array}{c}\text { Peso de 1000 } \\
\text { grãos (g) }\end{array}$ & $\begin{array}{c}\text { Teor de } \\
\text { hectolitro } \\
\text { proteína (\%) }\end{array}$ \\
\hline $\begin{array}{l}\text { Fontes de nitrogenio } \\
\text { Sulfato de amônia }\end{array}$ & $3464,17 \mathrm{a}^{1}$ & $39,56 \mathrm{a}$ & $77,83 \mathrm{a}$ & $14,21 \mathrm{a}$ \\
Uréia & $3815,42 \mathrm{a}$ & $40,29 \mathrm{a}$ & $78,09 \mathrm{a}$ & $14,57 \mathrm{a}$ \\
Nitrato de amônia & $3803,75 \mathrm{a}$ & $39,61 \mathrm{a}$ & $77,77 \mathrm{a}$ & $14,37 \mathrm{a}$ \\
\hline Epocas de aplicação & & & & \\
Plantio & $3707,92 \mathrm{a}$ & $39,23 \mathrm{~b}$ & $77,76 \mathrm{a}$ & $13,95 \mathrm{~b}$ \\
Perfilhamento & $3692,50 \mathrm{a}$ & $39,51 \mathrm{~b}$ & $77,90 \mathrm{a}$ & $14,14 \mathrm{~b}$ \\
Emborrachamento & $3682,92 \mathrm{a}$ & $40,73 \mathrm{a}$ & $78,01 \mathrm{a}$ & $15,07 \mathrm{a}$ \\
\hline Valores de F & & & & \\
Bloco & $1,46 \mathrm{~ns}$ & $1,27 \mathrm{~ns}$ & $2,08 \mathrm{~ns}$ & $1,35 \mathrm{~ns}$ \\
Fonte & $1,83 \mathrm{~ns}$ & $2,37 \mathrm{~ns}$ & $0,69 \mathrm{~ns}$ & $0,48 \mathrm{~ns}$ \\
Época & $0,01 \mathrm{~ns}$ & $9,02 * *$ & $0,45 \mathrm{~ns}$ & $5,42 * *$ \\
Fonte x Época & $1,09 \mathrm{~ns}$ & $1,73 \mathrm{~ns}$ & $1,65 \mathrm{~ns}$ & $2,69 \mathrm{~ns}$ \\
\hline C.V. (\%) & 13,82 & 2,30 & 0,83 & 6,18 \\
\hline
\end{tabular}

Obs: n.s. - não significativo ao nível de $1 \%$ de probabilidade; * - significativo ao nível de $5 \%$ de probabilidade; ** - significativo ao nível de $1 \%$ de probabilidade; 1 - as médias seguidas de letras diferentes são estatisticamente distintas entre si de acordo com o teste de Tukey, ao nível de 1\% de probabilidade.

Com relação ao teor de proteínas dos grãos, observou-se que a aplicação tardia de nitrogênio realizada no emborrachamento propiciou uma maior produção de proteínas nos grãos em relação à aplicação de nitrogênio realizada no perfilhamento e no plantio, fato também observado por Cuniberti (1996). Já entre as fontes não verificaram diferenças. 
Da mesma forma a aplicação de nitrogênio em cobertura na época do emborrachamento propiciou um maior peso de 1000 grãos em relação às aplicações antecipadas (Tabela 6), resultado semelhante foi obtido por Bredemeier e Mundstock (2001).

Devido ao maior peso de grãos e maior teor de proteína nos tratamentos que receberam adubação em cobertura na época do emborrachamento, esperava-se que o peso hectolítrico também apresentasse valores maiores nesses tratamentos, porém este fato não foi observado.

As diversas avaliações realizadas demonstraram uma mesma eficiência entre as fontes de nitrogênio testadas, o que poderia ser interessante para recomendações de adubação em cobertura, já que a uréia sabidamente a fonte nitrogenada mais econômica apresentou uma mesma eficiência em relação às demais fontes, os quais apresentam um custo maior (Tabela 7). Embora neste e em diversos outros trabalhos, não tenham sido observadas diferenças no rendimento de grãos utilizando uréia e outras fontes de nitrogênio, deve-se tomar muito cuidado na utilização da uréia em cobertura sem incorporação, pois sabe-se que suas perdas por volatilização da amônia são certamente maiores que outras fontes como o sulfato de amônia e nitrato de amônia, e também porque sua eficiência depende muito do ambiente, principalmente precipitação e temperatura fatores, não controláveis a campo para essa condição experimental, pode-se inferir que aplicação incorporada no plantio de uréia apresenta boa viabilidade prática, lembrando sempre dos cuidados do efeito danoso da salinidade da uréia para as sementes de trigo.
Tabela 7. Custo por $\mathrm{kg}$ de nitrogênio utilizando uréia, sulfato de amônia e nitrato de amônia.

\begin{tabular}{|c|c|c|c|}
\hline Fontes de $\mathbf{N}$ & $\begin{array}{c}\text { Custo por } t \\
\text { (R\$) }\end{array}$ & $\begin{array}{c}\text { Teor de } \mathrm{N} \\
(\%)\end{array}$ & $\begin{array}{c}\text { Custo } \\
(\mathrm{R} \$ / \mathrm{kg} \text { de } \mathrm{N})\end{array}$ \\
\hline Uréia & 806,39 & 45 & 1,79 \\
\hline Sulfato de Amônia & 556,08 & 21 & 2,65 \\
\hline Nitrato de Amônia & 685,09 & 33,5 & 2,05 \\
\hline
\end{tabular}

Fonte:SEAB/DERAL,out/2003.

\section{Conclusões}

Pelos resultados obtidos e nas condições em que foi conduzido o presente experimento pode-se concluir que:

a) As fontes de $\mathrm{N}$ não influenciaram nos parâmetros avaliados;

b) $\mathrm{O}$ fertilizante nitrogenado aplicado no emborrachamento, independente da fonte, propiciou maior teor de proteína nos grãos de trigo;

c) É viável a aplicação de todo o $\mathrm{N}$ na forma de uréia no plantio.

\section{Referências}

BREDEMEIER, C.; MUNDSTOCK, C. M. Estádios fenológicos do trigo para a adubação nitrogenada em cobertura. Revistas Brasileira de Ciência do Solo, Porto Alegre, v.25, n.2, p.317-323, abr.jun. 2001.

CANTARELLA, H.; SILVA, N. M.; ESPIRONELLO, A.; FURLANI, P.R.; WUTKE, A. C.P.; TOLEDO, S. V.; GALLO, P. B.; VILLELA, O. V.; QUAGGIO, J. A.; BERTON, R. S. Avaliação agronômica de fertilizantes nitrogenados. In: GOEDERT, W. J.; FILHO, F. A. D. Relatório bienal 19861987. Brasília. EMBRAPA/PETROBRÁS, 1988.

CUNIBERTI, M. B. Fertilizacion nitrogenada, proteinas y calidad del trigo. Córdoba: Estacion Experimental Agropecuária Marcos Juarez, 1996. (Informacion para Extension, n.33).

MALAVOLTA, E; VITTI, G. C.; OLIVEIRA, S. A. Avaliação do estado nutricional das plantas: princípios e aplicações. 2.ed. Piracicaba: Potafos, 1997.

MIELNICZUK, J. Adubação nitrogenada. In: OSORIO, E. A. Trigo no Brasil. Campinas: Fundação Cargil, 1982. 
NAKAYAMA, L. H. I.; FABRICIO, A. D.; SANTOS, R. F. Efeitos de doses e épocas de aplicação de nitrogênio para a cultura do trigo. In: REUNIÃO DA COMISSÃO NORTE BRASILEIRA DE PESQUISA DE TRIGO, 9, 1983, Brasília. Anais... Dourados. Embrapa-UEPAE Dourados, 1983. p.170-174.

OLIVEIRA, E. F.; BALBINO, L. C. Efeitos de fontes e doses de nitrogênio aplicados em cobertura nas culturas de trigo, milho e algodão. Cascavel, PR: OCEPAR, 1995. (Resultados de Pesquisa, n.1)
PERUZZO, G.; SIQUEIRA, O. J. F.; WIETHÖLTER, S.; Eficiência agronômica de fertilizantes nitrogenados para a cultura do trigo. Pesquisa Agropecuária Brasileira, Brasília, v.29, n.7, p.1027-1034, jul. 1994.

VIEIRA, M. I. O Trigo. Disponível em:http:// www.ruralnews.com.br/agricultura/graos/trigo.htm. Acesso em: 19 set. 2003.

VIEIRA, R. D.; FORNASIERI FILHO, D.; MINOHARA, L.; BERGAMASCHI, M. C. M. Efeito de doses e de épocas de aplicação de nitrogênio em cobertura na produção e na qualidade fisiológica de sementes de trigo. Científica, São Paulo, v.23, n.2, p.257-264, 1995. 